\title{
An Integrated Decentralized Energy Planning Model considering Demand-Side Management and Environmental Measures
}

\author{
Seyed Mahmood Kazemi and Masoud Rabbani \\ Department of Industrial Engineering, College of Engineering, University of Tehran, P. O. Box 11155-4563, Tehran, Iran \\ Correspondence should be addressed to Seyed Mahmood Kazemi; kazemi_m_s@yahoo.com
}

Received 28 February 2013; Revised 9 May 2013; Accepted 13 May 2013

Academic Editor: S. Venkata Mohan

Copyright (c) 2013 S. M. Kazemi and M. Rabbani. This is an open access article distributed under the Creative Commons Attribution License, which permits unrestricted use, distribution, and reproduction in any medium, provided the original work is properly cited.

\begin{abstract}
Decentralized energy planning (DEP) is looked upon as an indisputable opportunity for energy planning of villages, isolated islands, and far spots. Nonetheless, at this decentralized planning level, the value of demand-side resources is not fairly examined, despite enjoying great advantages. Therefore, the core task of this study is to integrate demand-side resources, as a competing solution against supply-side alternatives, with decentralized energy planning decisions and demonstrate the rewarding role it plays. Moreover, sustainability indicators (SIs) are incorporated into DEP attempts in order to attain sustainable development. It is emphasized that unless these indicators are considered at lower energy planning levels, they will be ignored at higher planning levels as well. Hence, to the best knowledge of the authors, this study for the first time takes into account greenhouse gas (GHG) emissions produced by utilization of renewable energies in DEP optimization models. To address the issues mentioned previously, multiobjective linear programming model along with a min-max goal programming approach is employed. Finally, using data taken from the literature, the model is solved, and the obtained results are discussed. The results show that DSM policies have remarkably contributed to significant improvements especially in terms of environmental indicators.
\end{abstract}

\section{Introduction}

Decentralized energy planning aims for efficient use of local resources to supply energy. DEP is an available option for satisfying energy needs of villages, isolated islands, and smallscale end users in a reliable, affordable, and environmentally sustainable way (Hiremath et al. [1]). To see some recent top researches conducted in the related area, the works of [2-7] are recommended. The DEP paramount feature is to provide an area-based DEP so that with the least economic and environmental costs develops alternate energy sources and satisfies energy requirements. References [8-11] are good example works done in the literature with focus on DEP modeling.

Energy demand management, also referred to as demandside management (DSM), includes activities that modify end use energy demand; for example, the activities aim to reduce peak demand. It is worth mentioning that peak demand management does not necessarily lead to reduction in total energy consumption, but it defers the need for investments in establishing new power plants. The most generally accepted definition of DSM is the one presented by Gellings in 1984 [12].

As discussed by Kreith and Goswami [12], DSM alternatives must be compared to supply-side alternatives. Thus, it entails considering and evaluating both supply-side and demand-side options in energy planning efforts. In the late 1980s, Ontario Hydro of Canada estimated that satisfying its customer peak demand via supply-side measures costs four times that of demand-side measures [13]. As a result, any energy planning model without simultaneously considering both sides is incomplete.

Although developing a model which considers a DEP with evaluating both supply-side and demand-side management measures is of great importance, it is not yet inclusive. The shortcoming is related to not taking SIs into account. To overcome this, we need to have such indicators quantified, which is of course a very challenging task [14] (see also [15, 16]). Evans et al. [17] ranked four renewable 
energy technologies, namely, photovoltaic, wind, hydro and geothermal, against several SIs using data extracted from the literature. These indicators include electricity generation cost, GHG emissions, availability and limitations of each technology, efficiency of energy transformation, land use requirements, water consumption, and social impacts. Based on their findings, wind technology outranked the others followed by hydro, photovoltaic, and geothermal technologies, respectively. Nonetheless, it should be pointed out that the ranking was provided for the global international conditions, whereas each technology can be considerably geographically affected.

To cover the mentioned gaps in the literature, in this paper a multiobjective linear programming formulation for a DEP problem is proposed that not only takes both supplyside and demand-side alternatives into account but also considers a number of important SIs against which five energy resources, including DSM options, are evaluated. It is worth mentioning that using multi-objective formulations for energy planning is commonplace in the literature; see, for example, [10, 18-21].

In a nutshell, the contributions of this paper can be summarized as follows.

(i) It is, to the best knowledge of the authors, for the first time that in DEP models supply-side and demandside options are treated equally.

(ii) It is, to the best knowledge of the authors, for the first time that in DEP models GHG emissions produced by renewable energy technologies during their life cycle are incorporated. It may be surprising that, for instance, for photovoltaic, the amount of produced GHG emissions is almost one quarter of natural gas emissions [22], while it had been a widespread supposition that GHG emissions of renewable energy technologies are insignificant.

(iii) A variety of important sustainable indicators, namely water consumption, land use, cost of generation, employment, and GHG emissions, are considered.

The rest of the paper is organized as follows. In the next section, materials and methods used are elaborated. In Section 3, results and discussions are provided. Finally, conclusion remarks are drawn in Section 4.

\section{Materials and Methods}

2.1. Materials. The data used in this paper are collected from the literature and are based on the global international conditions. To solve the model for a numerical example, Lingo 8.0 software was employed.

2.2. Mathematical Formulation. As stated before, five SIs are taken into account. These SIs are regarded as distinct objective functions. The notations used in this model along with the proposed integrated multi-objective formulation are presented below.
Notations. Sets are as follows:

$I$ : set of renewable energy technologies;

$J$ : set of end uses.

Parameters and variables as follows:

$w c_{i}$ : water consumption of $i$ th resource option $(\mathrm{kg} / \mathrm{kWh})$;

$\mathrm{GHG}_{i}$ : greenhouse gas emissions of the $i$ th resource option ( $\mathrm{g} \mathrm{CO}_{2-\mathrm{e}} / \mathrm{kWh}$ );

$l u_{i}$ : land use characteristic of $i$ th resource option $\left(\mathrm{m}^{2} / \mathrm{kWh}\right)$

$c_{i j}$ : electricity generation cost of resource $i$ for $j$ th end use (US\$/kWh);

$\mathrm{CDSM}_{j}$ : electricity saving cost using the implemented DSM program in the $j$ th end use (US\$/kWh);

$w_{i}$ : employment generation of $i$ th resource option (jobs/kWh);

$D_{j}$ : total energy demand for $j$ th end use $(\mathrm{kWh})$;

$\eta_{i j}$ : conversion efficiency for the $i$ th resource option for $j$ th end use;

$S_{i}$ : availability of the $i$ th resource option for $j$ th end use $(\mathrm{kWh})$;

$P_{j}$ : the maximum possible saving using the DSM program in the $j$ th end use $(\mathrm{kWh})$;

$\mathrm{SOBJ}_{j}$ : the required saving that is, to be achieved by the DSM program (kWh).

Decision variables:

$x_{i j}$ : optimal amount of $i$ th resource option for $j$ th end use (kWh);

$\mathrm{SDSM}_{j}$ : optimal saving in $j$ th end use using the implemented DSM program (kWh).

$$
\begin{aligned}
\text { Minimize total cost }= & \sum_{i} \sum_{j} c_{i j} \times x_{i j} \\
& +\sum_{j} \operatorname{SDSM}_{j} \times \mathrm{CDSM}_{j},
\end{aligned}
$$

Maximize total jobs created $=\sum_{i} \sum_{j} x_{i j} \times w_{i}$,

Minimize total water consumption $=\sum_{i} \sum_{j} x_{i j} \times w c_{i}$,

Minimize total greenhouse gas emissions

$$
=\sum_{i} \sum_{j} x_{i j} \times \mathrm{GHG}_{i} \text {, }
$$

Minimize total land used $=\sum_{i} \sum_{j} x_{i j} \times l u_{i}$. 
Which are subjected to the following:

$$
\begin{gathered}
\sum_{i} x_{i j}+\operatorname{SDSM}_{j} \geq D_{j}, \quad \forall j \in J, \\
\sum_{j} \frac{x_{i j}}{\eta_{i j}} \leq S_{i}, \quad \forall i \in I, \\
\operatorname{SDSM}_{j} \leq P_{j}, \quad \forall j \in J, \\
\operatorname{SDSM}_{j} \geq \mathrm{SOBJ}_{j}, \quad \forall j \in J, \\
x_{i j} \geq 0, \quad \operatorname{SDSM}_{j} \geq 0 .
\end{gathered}
$$

The objective function given in (1) minimizes the total electricity generation costs. As can be seen, costs associated with implementing the DSM program are also considered in the first objective function, and it is treated just like other energy resources. It means that saving a unit of electricity by implementing DSM can be treated like producing a unit of electricity by a power plant, provided that the data for the associated costs are available. Equation (2) maximizes total number of jobs created due to electrifying the area. It should be noted that since the data for the number of jobs created by implementing the DSM program were not found, assumed to be negligible in this paper. The objective function given in (3), (4), and (5) minimize total water consumption, greenhouse gas emissions, and total land used, respectively. Constraints (6) and (7) are demand and resource availability constraints, respectively. Constraint (8) denotes that the maximum expected saving that could be achieved by executing the DSM program is limited to a realistic upper bound. Constraint (9) forces energy planners to implement DSM programs and meet some predetermined energy efficiency goals [23]. Constraint (10) indicates that decision variables are nonnegative real numbers.

2.3. Methods. Before we can solve the model by Lingo 8.0 software, we must find a way to cope with the multi-objective nature of the proposed formulation. To do so, a min-max goal programming approach was applied to obtain the best mix of renewable energy sources. For further study about goal programming (GP) approaches, the respected reader is referred to [24]. Now, using GP approach the model presented in the previous subsection can be easily reformulated as a singleobjective linear programming formulation as presented in the following:

$$
\text { Minimize } \max \text { deviation }=d,
$$

Subject to $\alpha_{j} p_{j}+\beta_{j} n_{j} \leq d, \quad j=1,2, \ldots, 5$,

$$
\begin{gathered}
\sum_{i} \sum_{j} c_{i j} \times x_{i j}+\sum_{j} \operatorname{SDSM}_{j} \times \mathrm{CDSM}_{j} \\
-p_{1}+n_{1}=t_{1}, \\
\sum_{i} \sum_{j} x_{i j} \times w_{i}-p_{2}+n_{2}=t_{2}, \\
\sum_{i} \sum_{j} x_{i j} \times w c_{i}-p_{3}+n_{3}=t_{3},
\end{gathered}
$$

TABLE 1: Parameter values for renewable energy technologies.

\begin{tabular}{lcccc}
\hline & PV & Wind & Hydro & Geothermal \\
\hline $\begin{array}{l}w_{i}\left(10^{-4} \text { number }\right. \\
\text { of jobs produced/ }\end{array}$ & 0.27549 & 0.27549 & 1.466 & $0.4^{\mathrm{a}}$ \\
$\mathrm{kWh})$ & & & & \\
$\mathrm{wc}_{i}$ & 10 & 1 & 36 & 100 \\
$\mathrm{lu}_{i}$ & 0.046 & 0.072 & 0.411 & $0.05^{\mathrm{a}}$ \\
$\mathrm{GHG}_{i}$ & 90 & 25 & 41 & 170 \\
$S_{i}$ & 8000000 & 327000 & 555000 & $100000^{\mathrm{a}}$ \\
$c_{i j}(\forall j)$ & 0.398 & 0.02 & 0.039 & $0.03^{\mathrm{a}}$ \\
$\eta_{i j}(\forall j)$ & 0.13 & 0.39 & 0.9 & 0.15 \\
\hline
\end{tabular}

${ }^{\mathrm{a}}$ The value has been assumed by the authors.

$$
\begin{gathered}
\sum_{i} \sum_{j} x_{i j} \times \mathrm{GHG}_{i}-p_{4}+n_{4}=t_{4}, \\
\sum_{i} \sum_{j} x_{i j} \times l u_{i}-p_{5}+n_{5}=t_{5}, \\
\sum_{i} x_{i j}+\operatorname{SDSM}_{j} \geq D_{j} \quad \forall j \in J, \\
\sum_{j} \frac{x_{i j}}{\eta_{i j}} \leq S_{i}, \quad \forall i \in I, \\
\operatorname{SDSM}_{j} \leq P_{j}, \quad \forall j \in J, \\
\operatorname{SDSM}_{j} \geq \mathrm{SOBJ}_{j}, \quad \forall j \in J, \quad{ } \geq 0, \quad p_{j} \geq 0 .
\end{gathered}
$$

As shown above, parameter $d$ denotes maximum deviation from every target $\left(t_{j}\right)$. The parameter values $\alpha_{j}$ and $\beta_{j}$ are set by decision maker. In some sense, this method is similar to the weighted Tchebycheff approach except that here the optimum $z^{*}$ is replaced by target value.

\section{Results and Discussion}

In this section, in order to demonstrate the applicability of the model to real case problems, a numerical example based on the data obtained from the literature is developed. It should be pointed out that for the unavailable data, assumed values are considered. Tables 1 and 2 show the parameter values of the model that are either taken from $[10-12,17]$ or assumed by the authors.

The values of parameter $\mathrm{CDSM}_{j}$ in Table 2 are taken from [12]. For example, it is stated that a successful DSM program (2002 Massachusetts Electric-Residential Lighting Program) cost was \$3.3 million while it resulted in 18037 MWh energy saving. Therefore, the unit cost of energy saving using the implemented DSM program in the domestic sector is calculated as follows:

$$
\mathrm{CDSM}_{\text {domestic }}=\frac{3.3 \times 10^{6} \$}{18037 \times 10^{3} \mathrm{kWh}}=0.183(\mathrm{US} \$ / \mathrm{kWh}) \text {. }
$$


TABLE 2: Parameter values for different end uses.

\begin{tabular}{|c|c|c|c|c|}
\hline & Domestic & Agriculture & Community & Industry \\
\hline $\mathrm{CDSM}_{j}$ & 0.183 & 0.238 & 0.917 & 0.055 \\
\hline$D_{j}$ (the demand that is to be satisfied) & 258267 & 278915 & 5276 & 18815 \\
\hline Already supplied demand (ASD) & $116220^{\mathrm{a}}$ & $125512^{\mathrm{a}}$ & $2374^{\mathrm{a}}$ & $8467^{\mathrm{a}}$ \\
\hline$P_{j}(0.15 \times \mathrm{ASD})^{\mathrm{a}}$ & 17433 & 18827 & 356 & 1270 \\
\hline $\mathrm{SOBJ}_{j}\left(0.05 \times \mathrm{ASD}^{\mathrm{a}}\right.$ & 5811 & 6276 & 119 & 423 \\
\hline
\end{tabular}

${ }^{\mathrm{a}}$ The value has been assumed by the authors.

TABLE 3: Goal programming optimum solutions.

\begin{tabular}{lcccc}
\hline & $\begin{array}{c}\text { Domestic } \\
(\mathrm{kWh})\end{array}$ & $\begin{array}{c}\text { Agriculture } \\
(\mathrm{kWh})\end{array}$ & $\begin{array}{c}\text { Community } \\
(\mathrm{kWh})\end{array}$ & $\begin{array}{c}\text { Industry } \\
(\mathrm{kWh})\end{array}$ \\
\hline DSM & 17433 & 18827 & 119 & 1270 \\
PV & 100007.6 & 0 & 0 & 0 \\
Wind & 127530 & 0 & 0 & 0 \\
Hydro & 13296.4 & 245088 & 5157 & 17545 \\
Geothermal & 0 & 15000 & 0 & 0 \\
\hline
\end{tabular}

The way of calculating the other values are the same. In this example, a rural area is assumed that is partly electrified, but the most parts are not yet provided with electricity. An energy saving target ranging from 5 to 15 percent in the already electrified parts of the area is considered.

To solve the goal programming model proposed in Section 2.3, all $\alpha_{j}$ and $\beta_{j}$ values are set to be 0.5. The objective functions are also considered as presented below.

The first objective function:

$$
\frac{\left(\sum_{i} \sum_{j} c_{i j} \times x_{i j}+\sum_{j} \operatorname{SDSM}_{j} \times \mathrm{CDSM}_{j}-21528.53\right)}{21528.53} .
$$

The second objective function:

$$
\frac{\left(105.9338-\sum_{i} \sum_{j} x_{i j} \times w_{i}\right)}{105.9338} .
$$

The third objective function:

$$
\frac{\left(\sum_{i} \sum_{j} x_{i j} \times w c_{i}-4086100\right)}{4086100} .
$$

The fourth objective function:

$$
\frac{\left(\sum_{i} \sum_{j} x_{i j} \times \mathrm{GHG}_{i}-19418390\right)}{19418390} .
$$

The fifth objective function:

$$
\frac{\left(\sum_{i} \sum_{j} x_{i j} \times l u_{i}-24075.8\right)}{24075.8} .
$$

As a decision maker, the following target values are assigned to the five objective functions mentioned above, respectively.

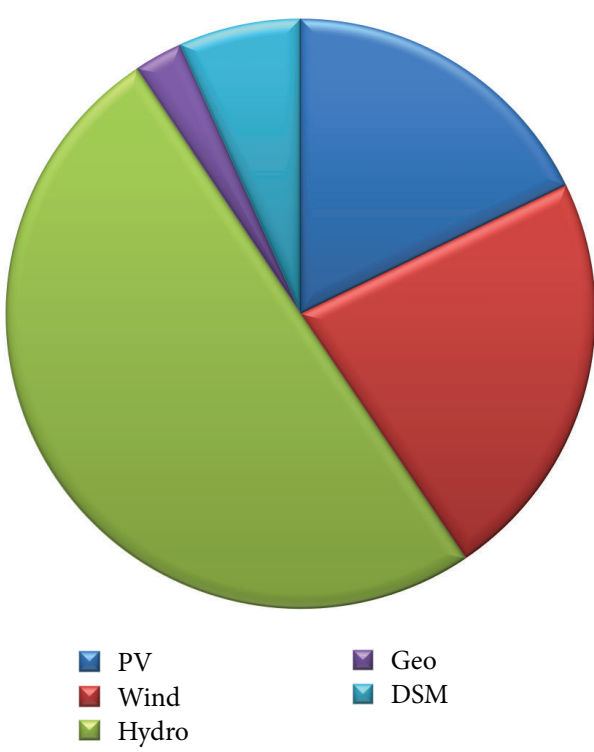

FIGURE 1: The role of each renewable energy source in electrifying the area under study.

The first objective function: 0.16 .

The second objective function: 0.7.

The third objective function: 1.2 .

The fourth objective function: 0.3 .

The fifth objective function: 2.7 .

Table 3 shows the outputs of Lingo 8.0 software for this numerical example.

Figure 1 shows the degree to which renewable energy sources have contributed to electrifying the area under study.

Using the solution given in Table 3, one can calculate the value of each individual objective function separately (Case 1). Also, by solving the original model presented in Section 2.2 once for each objective function (as a single-objective model) independently, the optimum value of each individual objective function is obtained (Case 2). Comparing the objective function values obtained in Case 1 with those obtained in Case 2 the following conclusions can be drawn.

(1) Goal programming results are more practical to implement.

(2) If the main limitations are water and land use requirements, minimizing GHG emissions and generation 
costs or maximizing employment will not be an attractive goal to attain.

(3) If financial resources are scarce, minimizing water consumption and land used will not be an attractive goal to attain.

(4) If maximizing employment is of the highest importance, similar to the previous, minimizing water consumption and land used will not be an attractive goal to attain.

From the results pointed out above, it can be summarized that provided that target values are determined carefully, the model could be useful under various geographical conditions.

\section{Conclusions}

In this study, an integrated multi-objective linear programming formulation was developed for decentralized energy planning such that demand-side management and environmental measures were also taken into account. Moreover, a number of important sustainability indicators were utilized upon which four renewable energy technologies were compared. Using goal programming approach, the proposed model was solved by Lingo 8.0 software. The findings indicate that fine choices of sustainability indicators for doing the decision-making process are extremely affected by the limitations the policy makers encounter. For example, poor countries suffer from scarce funding resources. Thus, when planning for their energy supplies, it is not so sensible to consider minimizing the land occupied by the supply technologies as an important criterion to pursue. Also, the obtained numerical results show that in the optimum solution hydro outranked the other renewable energy technologies followed by wind, photovoltaic, DSM resources, and geothermal, respectively. It is worth pointing out that DSM alternatives have greatly contributed together with the other energy supply technologies.

\section{Conflict of Interests}

The authors declare that they have no conflict of interests.

\section{References}

[1] R. B. Hiremath, B. Kumar, P. Deepak, P. Balachandra, N. H. Ravindranath, and B. N. Raghunandan, "Decentralized energy planning through a case study of a typical village in India," Journal of Renewable and Sustainable Energy, vol. 1, no. 4, Article ID 043103, 24 pages, 2009.

[2] N. L. Panwar, S. C. Kaushik, and S. Kothari, "Role of renewable energy sources in environmental protection: a review," Renewable and Sustainable Energy Reviews, vol. 15, no. 3, pp. 1513-1524, 2011.

[3] M.-A. Hessami, H. Campbell, and C. Sanguinetti, "A feasibility study of hybrid wind power systems for remote communities," Energy Policy, vol. 39, no. 2, pp. 877-886, 2011.

[4] J. R. San Cristóbal, "A goal programming model for the optimal mix and location of renewable energy plants in the North of
Spain," Renewable and Sustainable Energy Reviews, vol. 16, no. 7, pp. 4461-4464, 2012.

[5] J. Yang, W. Chen, B. Chen, and Y. Jia, "Economic feasibility analysis of a renewable energy project in the rural China," Procedia Environmental Sciences, vol. 13, pp. 2280-2283, 2012.

[6] K. Trapani, D. L. Millar, and H. C. M. Smith, "Novel offshore application of photovoltaics in comparison to conventional marine renewable energy technologies," Renewable Energy, vol. 50, pp. 879-888, 2013.

[7] C. Monteiro, I. J. Ramirez-Rosado, and L. A. FernandezJimenez, "Short-term forecasting model for electric power production of small-hydro power plants," Renewable Energy, vol. 50, pp. 387-394, 2013.

[8] T. Senjyu, D. Hayashi, A. Yona, N. Urasaki, and T. Funabashi, "Optimal configuration of power generating systems in isolated island with renewable energy," Renewable Energy, vol. 32, no. 11, pp. 1917-1933, 2007.

[9] R. B. Hiremath, S. Shikha, and N. H. Ravindranath, "Decentralized energy planning; modeling and application-a review," Renewable and Sustainable Energy Reviews, vol. 11, no. 5, pp. 729-752, 2007.

[10] D. S. Herran and T. Nakata, "Renewable technologies for rural electrification in Colombia: a multiple objective approach," International Journal of Energy Sector Management, vol. 2, no. 1, pp. 139-154, 2008.

[11] A. B. Kanase-Patil, R. P. Saini, and M. P. Sharma, "Integrated renewable energy systems for off grid rural electrification of remote area," Renewable Energy, vol. 35, no. 6, pp. 1342-1349, 2010.

[12] F. Kreith and D. Y. Goswami, Energy Management and Conservation Handbook, CRC, 2007.

[13] C. Beggs, Energy: Management, Supply and Conservation, Spon Press, 2009.

[14] N. Lior, "About sustainability metrics for energy development," in Proceedings of the 6th Biennal Workshop on Advances in Energy Studies, vol. 29, pp. 390-401, Graz, Austria, 2008.

[15] H. Hashim, P. Douglas, A. Elkamel, and E. Croiset, "Optimization model for energy planning with $\mathrm{CO}_{2}$ emission considerations," Industrial \& Engineering Chemistry Research, vol. 44, no. 4, pp. 879-890, 2005.

[16] Varun, R. Prakash, and I. K. Bhat, "Energy, economics and environmental impacts of renewable energy systems," Renewable and Sustainable Energy Reviews, vol. 13, no. 9, pp. 2716-2721, 2009.

[17] A. Evans, V. Strezov, and T. J. Evans, "Assessment of sustainability indicators for renewable energy technologies," Renewable and Sustainable Energy Reviews, vol. 13, no. 5, pp. 1082-1088, 2009.

[18] A. Alarcon-Rodriguez, G. Ault, and S. Galloway, "Multiobjective planning of distributed energy resources: a review of the state-of-the-art," Renewable and Sustainable Energy Reviews, vol. 14, no. 5, pp. 1353-1366, 2010.

[19] Y. A. Katsigiannis, P. S. Georgilakis, and E. S. Karapidakis, "Multiobjective genetic algorithm solution to the optimum economic and environmental performance problem of small autonomous hybrid power systems with renewables," IET Renewable Power Generation, vol. 4, no. 5, pp. 404-419, 2010.

[20] J. L. Bernal-Agustín, R. Dufo-López, and D. M. Rivas-Ascaso, "Design of isolated hybrid systems minimizing costs and pollutant emissions," Renewable Energy, vol. 31, no. 14, pp. 22272244, 2006. 
[21] P. S. Moura and A. T. de Almeida, "Multi-objective optimization of a mixed renewable system with demand-side management," Renewable and Sustainable Energy Reviews, vol. 14, no. 5, pp. 1461-1468, 2010.

[22] J. Wood, Local Energy: Distributed Generation of Heat and Power, IET, 2008.

[23] M. Dicorato, G. Forte, and M. Trovato, "Environmentalconstrained energy planning using energy-efficiency and distributed-generation facilities," Renewable Energy, vol. 33, no. 6, pp. 1297-1313, 2008.

[24] K. Deb, Multi-Objective Optimization Using Evolutionary Algorithms, Wiley, 2009. 


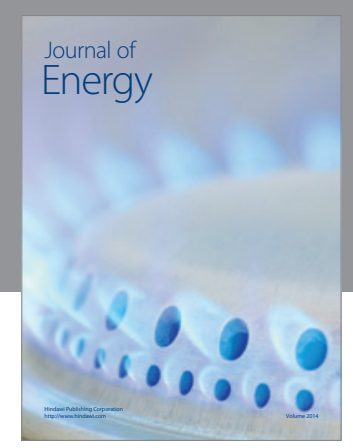

Journal of

Industrial Engineering
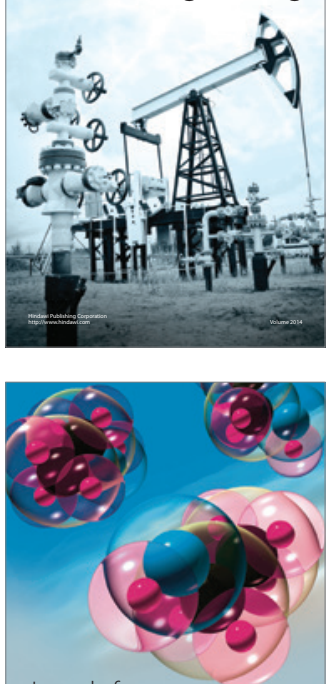

Fuels
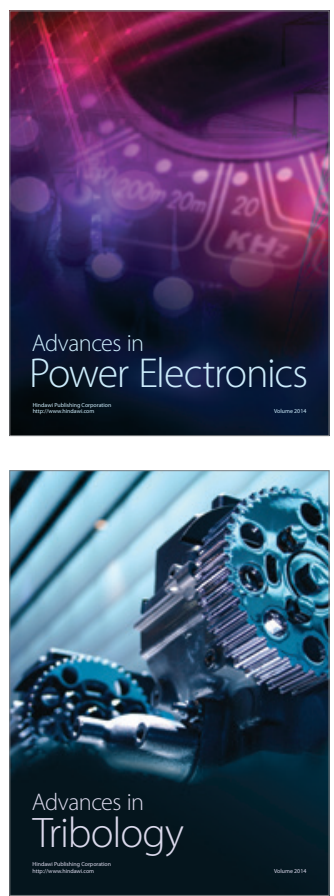

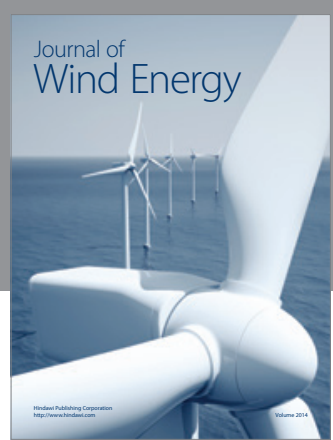

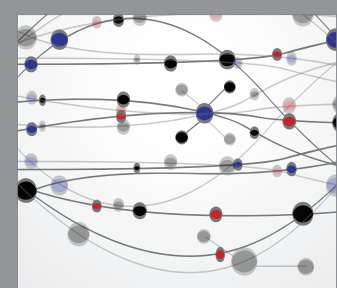

The Scientific World Journal

Submit your manuscripts at http://www.hindawi.com

Journal of

Structures
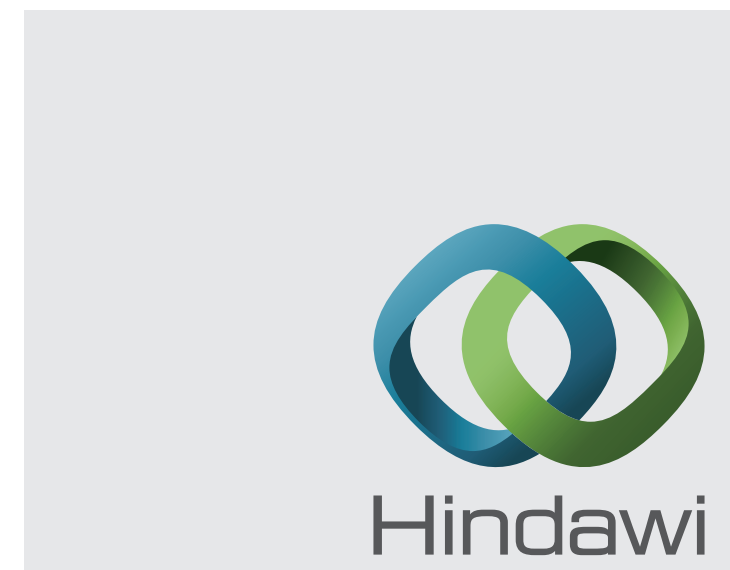

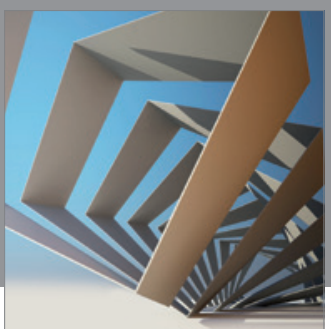

Rotating

Machinery
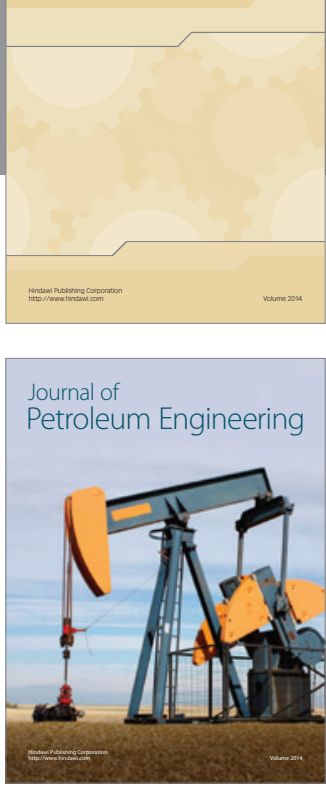

Journal of

Solar Energy
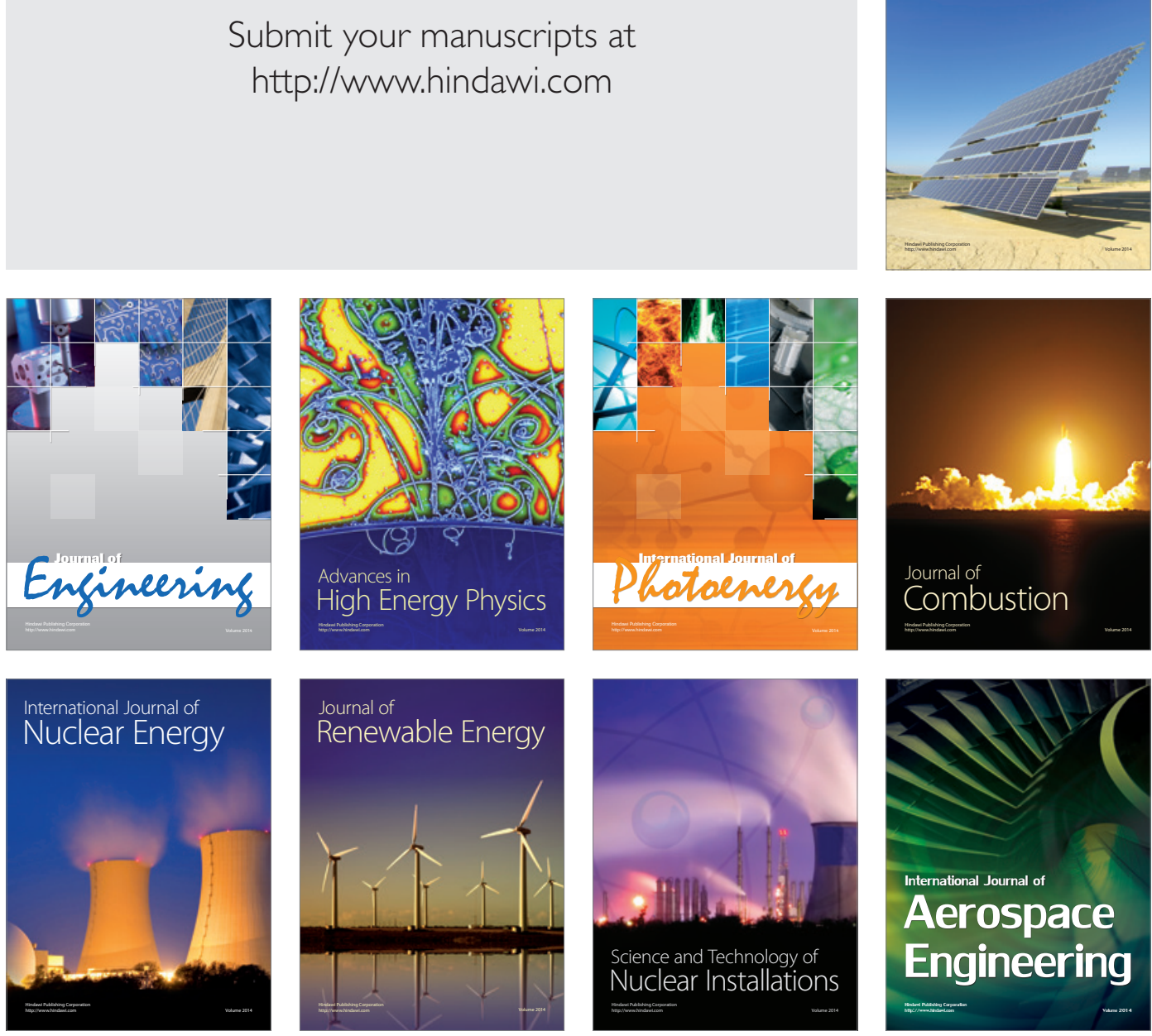